\title{
Hip Disarticulation for Severely Injured Lowerlimbs about 11 Cases and Literature Review
}

\author{
Koné Samba*, Dogba Eric, Godefroy Adibo, Pemboura Dominique, Koffi Akue, Ledion Anicet, \\ Bana Abdoulay, Agoh Serge
}

Traumatologyat Cocody's UHC (University Hospital Center), Abidjan, Cote d'Ivoire

Email: *k.samba06@gma il.com

How to cite this paper: Samba, K., Eric, D., Adibo, G., Dominique, P., Akue, K., Anicet, L., Abdoulay, B. and Serge, A. (2018) Hip Disarticulation for Severely Injured Lowerlimbs about 11 Cases and Literature Review. Open Journal of Orthopedics, 8, 67-76.

https://doi.org/10.4236/ojo.2018.82009

Received: January 3, 2018

Accepted: February 23, 2018

Published: February 26, 2018

Copyright $\odot 2018$ by authors and Scientific Research Publishing Inc. This work is licensed under the Creative Commons Attribution International License (CC BY 4.0).

http://creativecommons.org/licenses/by/4.0/

c) (i) Open Access

\begin{abstract}
Introduction: Hip disarticulation (HD) consists of a removal of the entire lower limb at the height of the hip-femoral joint. It is an extremely mutilating intervention with a major functional and psychological impact. We report 11 cases of hip disarticulation following severe trauma of the lower limb. The aim of the study is to analyze the frequency, the clinical aspect and present their management results and the patients' becoming. Patients and methods: A 13-year retrospective study was conducted in our traumatology department. Eleven cases of hip disarticulation were identified. We analyzed the following data: the epidemiological parameters (age, sex, accidentology), Clinico-radiological (gravity injury severity score (ISS), mangled extremity severity score (MESS), associated lesion), admission time, evolutionary aspects and finally the patients' becoming). Results: The series consisted of 3 males and 8 females, with an average age of 24 years. All experienced a HD following the lower limb severe traumatism due to a road accident. The category of victims was dominated by pedestrians. The average admission time was 13 hours with extremes of 9 and 28 hours. Our series average ISS was 28 with extremes of 15 - 69. The associated lesions were dominated by Gustilo Type III A III B open fractures. The mean MESS at admission was 10 with extremes from 8 to 14 . Complications were dominated by infection (at least 72\%) with a mortality rate of $36.36 \%$. Algohallucinosis affects all these patients post-operatively at varied degrees. Aggressive components and denial of bereavement were most noticeable. Only one patient was able to honor her Canadian prosthetic equipment. All the victims changed their personal and professional activities. Conclusion: $\mathrm{HD}$ is an extremely mutilating surgery with a major functional and psychological impact. Quality of life of the disarticulated patient is taught because of the persistence of the pain, the occurrence of a major motor han-
\end{abstract}


dicap and the impossibility of apparatus limiting the social and relational life.

\section{Keywords}

Disarticulation, Hip, Severely Injured, Limb

\section{Introduction}

Hip Disarticulation (HD) consists of a removal of the entire lower limb at the height of the hip-femoral joint. HD is usually performed for a poor prognosis tumoral cause and less often for severe trauma of the lower limb [1] [2]. It is an extremely mutilating surgery [3] with a major functional and psychological impact [2] [4]. Its equipment is made thanks to prosthesis with ischiatic support known as "Canadian prosthesis" [4]. Indeed, thanks to bypass grafting and transplantation, traumatic limb amputations are in net decline. Recent and ongoing progress in vascular surgery justifies all attempts to retain the limb however few data are available on HD post-traumatic cases.

In the event of lower limb severe trauma, multidisciplinary teams engage in complex limb salvage programs [5]; in our current practice realities HD is unfortunately the only alternative "indication of reason". We report a series of HD after severe trauma of the lower limb.

The aim of our study was to describe the epidemiological and clinical profile of HD victims at Cocody's UHC (university hospital center) and analyze their becoming and quality of life.

\section{Patients and Methods}

This retrospective and mono-centric series included all patients aged 15 years and older, with a complete medical record having suffered a HD following a lower limb(s) severe trauma from March 2004 to February 2017. Tumoral, arteritic, malformative reasons for HD were excluded.

The indication was made in front of irreparable vascular lesions (n) or the severity of the soft tissue (n). The mangled extremity severity score (MESS) [6] was used as element to take a decision. The indication of HD was made when this score was equal to or greater than 7 score before any HD, patient and/or family consent (verbal, written) was sought. The intervention was performed for all in emergencies under general anesthesia. The minimum follow-up was one year.

We analyzed the following data: epidemiological parameters (age, sex, accidentology), clinico-radiological (ISS [7], MESS, associated lesions, HD cause, admission delay), the evolutionary aspects (time of healing and hospitalization, complications) and the psychosocial impact. A functional evaluation was assessed by the perimeter of walking, the use of cane, the personal activities recovery. 


\section{Results}

\subsection{Epidemiology}

Thirteen HD have been identified, of which 02 files not found. Eleven HD files were found among 6379 hospitalization records including 319 amputations cases performed during the study period.

Amputations represented around 5\% of our hospitalization cases. HD represents about $0.4 \%$ of amputations (any level and any cause combined). HD frequency is $0.002 \%$ of hospitalizations. The annual incidence was 0.92 per year.

The series consisted of 3 males and 8 females. The mean age at the time of the trauma was 24 years old $(16-58)$ (Table 1$)$.

\subsection{Patients and Accidentology}

All were victims of traffic accidents. The category of users was dominated by pedestrians ( 7 cases), 03 victims were passengers on a two-wheeled vehicle and one victim was a passenger in a common transport vehicle.

The average admission time was 13 hours with extremes of 9 and 28 hours.

\subsection{Pre-Operative Data}

Our series average Injury Severity Score (ISS) was 24 with extremes of 16 - 51.

The associated lesions (Table 2) were dominated by open type III A III B Gustilo's fractures.

The average MESS (Table 3) at admission was 10 with extremes of 8 to 14 .

The HD indication was asked when the MESS score was greater than 7 .

These severe traumas were composed of a vascular section (femoral artery) (n $=4$ cases) (Figure 1); following decaying trauma and irreparable soft tissues ( $\mathrm{n}=$ 6 cases) including 2 cases of traumatic limb amputation in the thigh (Figure 2)

Table 1. Distribution of patients by age and sex at the accident time.

\begin{tabular}{|c|c|c|c|c|}
\hline & \multirow{2}{*}{ Effective } & \multicolumn{3}{|c|}{ Distribution by age groups } \\
\hline & & $<29$ years & 30 - 50 years & $>51$ years \\
\hline General population & 11 & 6 & 2 & 1 \\
\hline Male & 3 & 1 & 1 & \\
\hline Female & 8 & 5 & 3 & 1 \\
\hline
\end{tabular}

Table 2. Distribution of patients by associated lesions.

\begin{tabular}{cc}
\hline Associated lesions & Effective \\
\hline Cranial trauma & 5 \\
Intra pelvis lesions & 2 \\
Homolateral limb open fracture & 6 \\
Other limbs fracture & 5 \\
Thoracic lesions & 4 \\
\hline
\end{tabular}


Table 3. The mangled extremity severity score.

\begin{tabular}{ccc}
\hline & Factors & Score \\
\hline Skeletal/soft-tissue injury & Low energy (stab; simple fracture; pistol gunshot wound) & 1 \\
& Medium energy (open or multiple fractures, dislocation) & 2 \\
Medium energy (open or multiple fractures, dislocation) & 3 \\
Very high energy (high speed trauma + gross & contamination) & 4 \\
Limb ischemia & Pulse reduced or absent but perfusion normal & $1^{*}$ \\
Pulseless; paresthesias, diminished capillary refill & $2^{*}$ \\
Shock & Cool, paralyzed, insensate, numb & $3^{*}$ \\
Systolic BP always > 90 mm Hg & 0 \\
Hypotensive transiently & 1 \\
Persistent hypotension: & 2 \\
$<30$ & 0 \\
& 30 - 50 & 1
\end{tabular}

*doubled score for ischemia $>6$ hours. A MESS score of 7 means a 100\% prognosis value in favor of amputation.
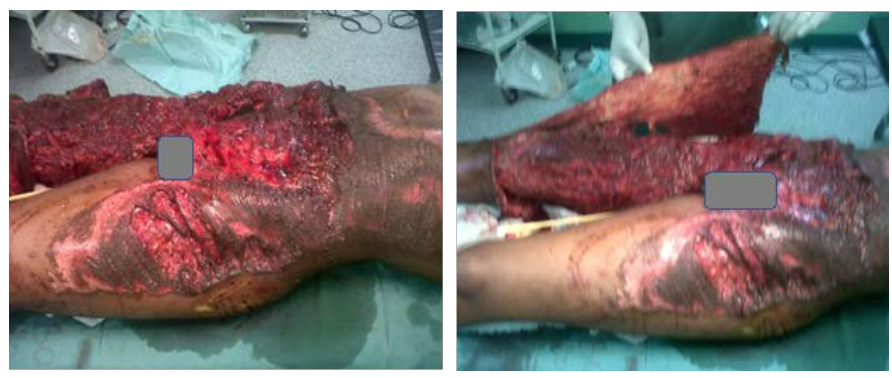

Figure 1. Clinical appearance of a victim with severe soft tissue disruption and a section of the femoral artery.
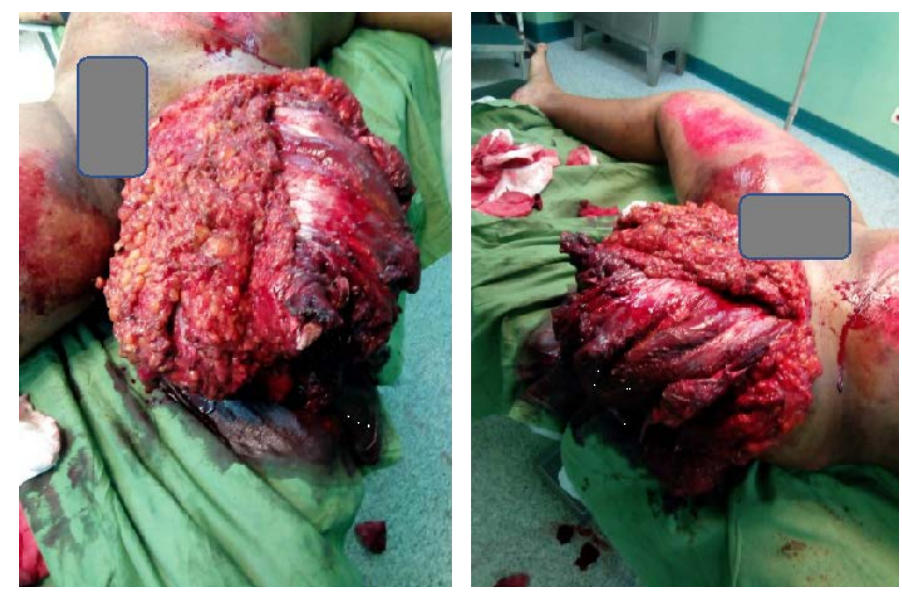

Figure 2. Clinical appearance of a traumatic amputation in the thigh with a significant tearing of the soft parts. 
and in front of 01 case of post-fracture gas gangrene (open fracture of the femur). The average operating time was 8 hours with extremes of $4-8$ hours. The dominant side was involved in 7 on 9 cases. None bilateral HD.

\subsection{Post Operative Data}

The average hospitalization length was of 02 months 15 days with extremes ranging from 8 up to 72 days.

Complications were dominated by infection (at least 72\%) (Figure 3) and dehiscence of the operative wound (63\%) (Table 4).

We had four deaths ( 1 by thromboembolic complication, 3 by sepsis) during hospitalization, then a hospital mortality rate of $36.36 \%$.

Five patients underwent secondary resection for deep sepsis, 05 patients required directed healing with a thin skin secondary graft. On 02 patients, a secondary suture was made.

\subsection{Evolutive Monitoring Data}

The Nottingham Heath [8] profile was adapted to the requirements of our study by separately analyzing the intensity of pain, function and psychosocial impact (Table 4). Phantom-limb pain (algohallucinosis) was assessed by the Analgesic Visual Scale. Functional evaluation was appreciated by the walking perimeter (WP), cane use, and personal activities recovery.

Emotional reactions were analyzed according to the grief work schema, established by Kübler-Ross [9].

The 7 survivors have all reviewed. Algohallucinosis affects all these patients postoperatively to varying degrees (Table 5).

Only one patient was able to honor the Canadian prosthesis and her WP was. One patient remained in the wheelchair and the others kept the canes with a WP of 1 - 5 hours per day. At the psychological level, denial $(n=6)$, and aggression $(\mathrm{n}=6)$ were most noticed.

Six patients changed their personal and professional activities.

\section{Discussion}

This descriptive monocentric study focused on HD after lower limb severe trauma.
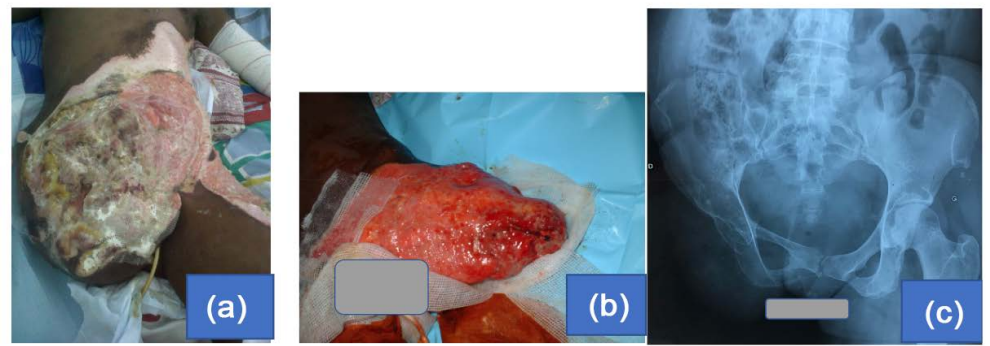

Figure 3. Clinical appearance of local sepsis (a), postoperative dehiscence with excessive bud (b), Antero-posteriorpelvis X-ray in post-opérative (c). 
Table 4. Distribution of patients by complications.

\begin{tabular}{ccc}
\hline Complications types & Effective & Percentage \% \\
\hline Dehiscence operative wound & 7 & 63.63 \\
Local sepsis & 10 & 90.90 \\
Deep sepsis & 8 & 72.72 \\
Thromboembolic complication & 01 & 0.9 \\
Non painful phantom limb & 11 & 100 \\
Death & 04 & 36.36 \\
Septicemia & 08 & 72.72 \\
Algohallucinosis & 3 & 27.27 \\
\hline
\end{tabular}

Table 5. Distribution of patients by psychosocial and functional parameter.

(a)

\begin{tabular}{cccc}
\hline Psychosocial parameter & & Effective & Percentage \% \\
\hline \multirow{3}{*}{ Algohallucinose } & Minimal & 01 & 14.28 \\
& Important & 05 & 71.42 \\
Grief Work & Very importante & 01 & 14.28 \\
& Denial & 06 & 85.71 \\
& Aggressivity & 06 & 85.71 \\
& Depression & 03 & 42.85 \\
& Haggling & 01 & 14.28 \\
& Acceptation & 01 & 14.28 \\
\hline
\end{tabular}

(b)

\begin{tabular}{cccc}
\hline \multicolumn{1}{c}{$s$} & Effective & Percentage \% \\
\hline Apparatus & & 01 & 14.28 \\
Without apparatus & & 06 & 85.71 \\
Cane use & & 05 & 71.42 \\
Wheelchair & $<$ hour & 01 & 14.28 \\
Walking perimeter & 1 - 5 hours & 01 & 14.28 \\
& $>5$ hours & 05 & 71.42 \\
& Same post & 01 & 14.28 \\
& Disposition & 00 & 00.00 \\
Recovery activity & Retraining & 01 & 14.28 \\
& Unemployment & 03 & 42.85 \\
& & 03 & 42.85 \\
\hline
\end{tabular}

The limit of our study is its retrospective character and the small sample size despite a long study period. This number reflects the rarity of this indication in our current trauma and its low frequency in the literature gives this series of 
cases a certain value to comment. Causes of amputation differ from one country to another [10] [11].

Although in the developed country countries arterial insufficiency of the lower limbs [12] is the leading cause of lower limb amputation, in our underdeveloped countries trauma constitutes the first cause [10] [13] [14]. This work confirms this observation because all our patients were victims of traffic accidents. Severe lower limbs lesions occur following a violent trauma in a context of polytraumatism with ISS very high score [7].

HD due to traumatic cause represents less than $1 \%$ limb amputation [10] [15].

Our series is distinguished by a young average age (24 years) [10] [13] and also by the women majority proportion. The traumatic origin is primarily a traffic accident that affected mostly pedestrian victim.

Currently, there is no consensus on the therapeutic management of lower limb injuries [16]. Should we amputate early or try to save the member at any cost?

The MESS score [6] [17] is useful in decision-making even if some authors oppose it a little discriminating and low sensitivity (46\%). For Johansen et al. [6] a score greater than 7 implies a systematic amputation whereas for Lange et al. [18] a crush with ischemia greater than 6 hours is an absolute criterion of primary amputation.

Regarding these parameters, it appears that our HD indications seem reasonable seeing the long admission period and the severity of the lesions. On the other hand, some of our patients (n) had such soft parts decay that the choice of HD seemed less heavy for them. Indeed, the commitment to a reconstruction process would expose the patient to months of hospitalization, infectious complications, iterative intervention and a highly uncertain outcome. This was the case with patients, on whom we therefore realized a HD of "reason".

The mortality of $36.36 \%$ in our series is high in a young active population apparently without obvious comorbidity.

This could be related to the high frequency of postoperative complications (72\%). In fact, the observed deaths occurred in the first post-operative month and are secondary to infectious (septicemia) and thromboembolic complications.

Thus, these lower limbs severe traumatisms have an important septic evolutionary potential in relation to a delay of management on a presumably septic medium (staining of the initial lesions).

Moreover, this delay in admission can be explained by the inefficiency of the organization and evacuation system of traffic accidents victims to hospitals; and also, by the lack of financial resources. These reasons are evoked by Tidjani [10].

According to the literature, the amputees' mobility is directly related to the level of amputation and the type of equipment [1]. HD is an extremely mutilating procedure with major functional repercussions [2] [4]. In case of HD the equipment uses femoral sockets with integrated ischion called "Canadian prosthesis" [1] [4]. The use of prosthesis is an essential parameter in the rehabilita- 
tion and overall well-being of the amputated patient [1]. In our underdeveloped countries, the fitting possibilities for this type of amputation are insufficient [15] [19]. Moreover the prosthesis cost occupies a preponderant part in the management of the HD except the expenses related to the surgical act and the hospitalization. For these reasons, $90 \%$ of our patients could not be fitted. This constitutes a major obstacle to their functional and social independence, especially as it affects a young active population.

All felt phantom limb pain to varying degrees. This pain is well known in the literature even though it still poses a real problem of management [20].

Regarding the grief work, we notice a psychological impact in our series. Indeed Kübler-Ross E. [9] reports that an amputee goes through 5 mandatory phases that lead or not to the acceptance phase. These five phases are not necessarily all past, nor executed in the same order, nor at the same speed. In our series the phases of haggling and acceptance were not yet performed for most victims.

If for some the psychological management of limb amputees must be early and mandatory; however, in our current practices, in traumatic pathology the vital emergency unfortunately leaves little time for the eventualities of psychological patient and/or the family preparation. This could explain the high frequency of psychological impact the psychosocial impact and personal activities recovery.

\section{Conclusions}

The epidemiological profile of a HD for severe lower limb trauma is that of a young adult at the beginning of a professional career, traumatized on the road by vehicles of all kinds.

The decision to disarticulate may appear to be "simple and direct" when the patient's life is in danger or in case of irreparable vascular injury; but it becomes more difficult or even reasonable to take into account the seriousness of the soft parts decay considering the delay of admission and our conditions of work.

The complications are often dominated by infection. Quality of life of the disarticulated patients is bad because of the persistence of the pain, the occurrence of a major motor handicap and the impossibility of apparatus limiting the social and relational life.

The HD itself is a trouble that the patient must face with all possible support of the medico-surgical team and family.

Limits of our series of case study are the retrospective nature of the study, and it comes from clinical observations which does not represent the population at risk or the magnitude of the phenomenon.

\section{Consent}

This study was approved by local ethic committee. These patients and the families were informed that data from the case would be submitted for publication and provided their consent accordingly. 


\section{Conflict of Interests}

The authors declare that they have no competing interests.

\section{Author's Contributions}

All the authors contribute to the writing of this manuscript and have read and approved the final version.

\section{References}

[1] Menager, D. (2002) Amputations du membre inférieur et appareillage. Encycl Méd Chir (Editions Scientifiques et Médicales Elsevier SAS, Paris) Applied Locomoteur, $15,8966$.

[2] Kirsch, J.M. (1980) La desarticulation de hanche. Thèse, Paris.

[3] Camilleri, A., Anract, P., Missenard, G., et al. (2000) Amputations et désarticulations des membres. Membre inférieur. Encycl Méd Chir (Editions Scientifiques et Médicales Elsevier SAS, Paris) Techniques chirurgicales-Orthopédie-Traumatologie, 44, 109.

[4] Menager, D., Ghiesa, G. and Lerner, J.M. (1996) La prothèse canadienne. À propos de, 131 .

[5] Frisch, H.M., Andersen, R.C., Mazurek, M.T., et al. (2013) The Military Extremity Trauma Amputation/Limb Salvage (METALS) Study: Outcomes of Amputation versus Limb Salvage Following Major Lower-Extremity Trauma. The Journal of Bone \& Joint Surgery, 95, 138-145. https://doi.org/10.2106/JBJS.K.00734

[6] Johansen, K., Daines, M., Howey, T. and Hauser, S.T. (1990) Objective Criteria Accurately Predict Amputation Following Lower Extremity Trauma. The Journal of Trauma, 30, 568. https://doi.org/10.1097/00005373-199005000-00007

[7] Baker, S.P., O'neill, B., Haddon, W., et al. (1974) The Injury Severity Score: A Method for Describing Patients with Multiple Injuries and Evaluating Emergency Care. Journal of Trauma and Acute Care Surgery, 14, 187-196. https://doi.org/10.1097/00005373-197403000-00001

[8] Demet, K., Guillemin, F., Martinet, N., et al. (2002) Nottingham Health Profile: Reliability in a Sample of 542 Subjects with Major Amputation of One or Several Limbs. Prosthetics and Orthotics International, 26, 120-123. https://doi.org/10.1080/03093640208726634

[9] Kübler-Ross, E. (1975) On Death and Dying. Bulletin of the American College of Surgeons, 60, 12-15.

[10] Tidjani, I.F., Chigblo, P., Madougou, S., et al. (2017) Profil épidémiologique et clinique des amputations de membres de l'adulte à Cotonou. Revue de Chirurgie Orthopédique et Traumatologique, 103, 682-687. https://doi.org/10.1016/j.rcot.2017.05.001

[11] Agu, T.C. and Ojiaku, M.E. (2016) The Indications for Major Limb Amputations: 8 Years Retrospective Study in a Private Orthopaedic and Trauma Centre in the South-East Nigeria. Journal of Clinical Orthopaedics and Trauma, 7, 242-247. https://doi.org/10.1016/j.jcot.2016.03.006

[12] Zingg, M., Nicodème, J.D., Uçkay, I., Ray, A., et al. (2014) Amputations du membre inférieur: indications, bilan et complications. Revue Médicale Suisse, 10, 2409-2413.

[13] Essoh, J.B., Kodo, M. and Dje, V.D.B. (2009) Limb Amputations in Adults in an Ivorian Teaching Hospital. Nigerian Journal of Clinical Practice, 12. 
[14] Abalo, A., Sanon, G., Walla, A., et al. (2011) Amputations de membres inferieurs: aspects epidemiologiques, facteurs etiologiques et aspects evolutifs. Journal de la Recherche Scientifique de l'Universite de Lome, 13, 61-67.

[15] Manou, B.K., Bombo, J., Alloh, A.D., et al. (2009) Amputation de membres inférieurs et appareillage: expérience du centre d'appareillage «Vivre debout» à Abidjan. Journal de Réadaptation Médicale: Pratique et Formation en Médecine Physique et de Réadaptation, 29, 152-157. https://doi.org/10.1016/j.jrm.2009.09.001

[16] Barla, M., Gavanier, B., Mangin, M., et al. (2017) L'amputation peut-elle être un choix thérapeutique dans les traumatismes menaçant les membres inférieurs? Revue de Chirurgie Orthopédique et Traumatologique, 103, 677-681.

https://doi.org/10.1016/j.rcot.2017.07.002

[17] Kumar, M.K., Badole, C.M. and Patond, K.R. (2007) Salvage versus Amputation: Utility of Mangled Extremity Severity Score in Severely Injured Lower Limbs. Indian Journal of Orthopaedics, 41, 183. https://doi.org/10.4103/0019-5413.33679

[18] Lange, R.H., Bach, A.W., Hansen, J.S. and Johansen, K.H. (1985) Open Tibial Fractures with Associated Vascular Injuries: Prognosis for Limb Salvage. The Journal of trauma, 25, 203-208. https://doi.org/10.1097/00005373-198503000-00006

[19] Oliveira, Y.S., Angoue, J.M., Nguimbi Mbadinga, A.M., et al. (2014) Amputation des membres inférieurs et appareillage: expérience du centre de réadaptation et d'appareillage pour handicaps «La Raison de Vivre, Le Droit d'Espérer» à Libreville. Journal de Réadaptation Médicale: Pratique et Formation en Médecine Physique et de Réadaptation, 34, 53-59. https://doi.org/10.1016/j.jrm.2014.01.002

[20] Karanikolas, M., Aretha, D., Tsolakis, I., et al. (2011) Optimized Perioperative Analgesia Reduces Chronic Phantom Limb Pain Intensity, Prevalence, and Frequency: A Prospective, Randomized, Clinical Trial. Anesthesiology: The Journal of the American Society of Anesthesiologists, 114, 1144-1154.

https://doi.org/10.1097/ALN.0b013e31820fc7d2 